\title{
What's New in the Recognition and Management of Septic Shock in Children: Dos and Don'ts
}

\author{
Andrew C. Argent
}

Published online: 6 January 2013

(c) Springer Science + Business Media New York 2013

\begin{abstract}
While there has been a reduction in the number of children dying of septic shock in the richer countries of the world, septic shock remains an important cause of both mortality and morbidity for children across the world. Major reduction in the incidence of septic shock will depend on the implementation of public health measures, including immunization. Improvements in outcome of pediatric septic shock have been closely linked to early recognition (although this may be challenging in many situations); early antibiotic administration; early and appropriate fluid administration and subsequent escalation of critical care. A particular challenge has been the development and implementation of systems to ensure that these elements of management are reliably and efficiently implemented in children (even in well-resourced countries). Recent studies have highlighted the complexity of caring for patients with acute severe sepsis and septic shock in countries with fewer resources, and there is an urgent need for further studies to elucidate the implications of these studies for the management of children with septic shock, particularly in settings where additional critical care support such as inotropic or ventilator support may not be readily available.
\end{abstract}

Keywords Children - Septic shock - Recognition · Management · Resuscitation · Ventilation

A. C. Argent ( $\square)$

School of Child and Adolescent Health, Institute of Child Health, Red Cross War Memorial Children's Hospital, Klipfontein Road, Rondebosch, Cape Town 7700, South Africa e-mail: Andrew.argent@uct.ac.za

\section{Introduction}

Immunization against organisms such as Haemophilus influenza B, Neisseria meningitidis and Streptococcus pneumonia has substantially reduced the impact of acute bacterial infections on children in richer nations of the world $[1,2]$, but there are many countries where access to immunization is limited while exposure to infection is high and sepsis remains a major cause of death in children and young infants [3] across the world. Newborn infants are particularly at risk, and sepsis is the major factor in nearly $30 \%$ of the approximately 4 million newborn deaths that occur annually across the world [4]. Even in areas where the overall bacterial sepsis rate has dropped significantly, the hospital mortality related to bacterial sepsis had not improved [5•].

Improved recognition and early, goal-directed, timesensitive management of septic shock has resulted in a dramatic reduction in the mortality of children who present in septic shock. In the 1960s mortality from septic shock in children was close to $100 \%$ [6], and in many countries today mortality from pediatric septic shock is $10 \%$ or less $[7,8]$ (better in previously well children than in those with chronic illness) although there may still be significant associated morbidity [9-11].

An underlying theme is that significant improvements in the outcomes of patients with septic shock have been achieved by the use of structured approaches to management [12-14], and many of the interventions that have made the most impact have been relatively simple $[15,16]$.

This review will consider factors that should be weighed in the recognition of septic shock in the clinical context, and then consider advances and controversies in the management of children with septic shock. It will not focus on the challenges of treating neonates and particularly preterm infants with septic shock. 


\section{Recognition}

Recognition of the possibility of septic shock as a cause of symptoms in a particular child is fundamental to the management of septic shock as the earlier therapy is initiated, the better the outcome is likely to be $[12,17,18]$. Different age groups are characterized by different organisms and pathophysiological mechanisms. There are different responses to sepsis in adults and children (as recently reviewed by Aneja and Carcillo [19]), in children of different ages [20], and in neonates (in whom responses even vary between term and preterm infants) [20]. Adults typically present with "warm shock" (high cardiac output and low systemic vascular resistance manifesting with tachycardia, flash capillary refill, wide pulse pressures) while children more frequently present with "cold shock" (low cardiac output and high systemic vascular resistance manifesting with tachycardia, mottled pale skin, prolonged capillary refill and decreased peripheral pulses). Not only are there age-related differences in hemodynamic presentations, but the particular organisms (or source of the organisms) may affect the nature of the hemodynamic presentation in severe sepsis. Furthermore the presentations of septic shock are dynamic and may change over time, even in the same patient.

While recognition of septic shock may be relatively straightforward in the context of an intensive care unit that deals with many such patients, it is much more challenging to ensure that early signs of septic shock are recognized in children initially presenting to healthcare services where such problems are much less frequent [21, 22]. Studies of meningococcal disease suggest that while the "full-blown" picture may be easy to recognize, the clinical features in the early phase of the disease may be very non-specific and subtle [23]. Early diagnosis is also difficult in settings where clinicians are not dealing with many children as the clinical features of septic shock differ between adults and children [19].

Clinical signs of sepsis are the result of an interaction between the particular pathogen(s) and the responses of the particular patient to that pathogen [24]. Given the wide range of potential pathogens and the range of host responses, it is inevitable that there will be a range of clinical features related to septic shock. This is further complicated by the range of hemodynamics [25, 26] encountered in children with septic shock. In a recent study of patients with fluid resistant (who required $40 \mathrm{~mL} / \mathrm{kg}$ or more of resuscitation) septic shock [27], patients with central-line-associated infection (predominantly Staphylococcus epidermidis and Klebsiella pneumoniae) presented with high cardiac output and low systemic vascular resistance while patients with community acquired sepsis presented with low or normal cardiac output and high systemic vascular resistance. Furthermore, the clinical picture of "septic shock" can occur in response to a wide range of pathogens including viruses [28-30], malaria [31], rickettsiae and a range of bacterial pathogens.

Recognition of septic shock requires first the recognition of shock, and then the attribution of that shock to infection. Data from primary care settings suggest that clinical and laboratory signs may be useful in the diagnosis of severe sepsis in developed countries [22, 23, 32•, 33]. Clinicians' "gut feelings" (including a sense from the parents that this illness was "different") are also significant [34].

Clinical definitions for septic shock as laid out in the ACCM/PALS [Pediatric Advanced life support] guidelines [35] focus on the clinical features of shock which include: "sustained tachycardia" (the definitions of which depend on age, and which may be absent in hypothermic patients), diminished peripheral pulses compared with central pulses, delayed capillary refill (defined as $>2$ s) or flash capillary refill, altered mental status, mottled cool extremities, or decreased urine output $(<1 \mathrm{~mL} / \mathrm{kg} / \mathrm{h})$ —all signs of inadequate end-organ perfusion. Hypotension $(<5$ th percentile for age) is considered confirmatory but not necessary [35]. It is important to note that this clinical definition is different from that laid out in consensus statements on definitions of severe sepsis in children [36] which were focused on providing definitions for clinical research, and not on ensuring that sepsis was diagnosed early and effectively. In particular previous administration of fluid boluses or need for vasoactive drugs are not required in the ACCCM/PALS guidelines (see Table 1). Use of different guidelines or definitions for septic shock is related to significant differences in diagnosis [37].

Although Carcillo et al. [9] have shown that early treatment of septic shock based on clinical signs such as capillary refill has improved outcomes, other studies [38, 39] have shown poor reproducibility between observers in the assessment of capillary refill and in the prognostic significance of the sign. Tachycardia (particularly persistent tachycardia), together with delayed capillary refill were features of shock in a large group of children [9], and in that study persistence of tachycardia, delayed capillary refill and systolic hypotension were strongly associated with mortality. The shock index (ratio of heart rate to systolic arterial pressure) [9, 40] may be a useful clinical parameter to highlight the presence of shock (and to monitor response to therapy).

In neonates it may be impossible to differentiate septic shock from duct-dependent cardiac lesions and prostaglandin infusions should be initiated together with antibiotic therapy and appropriate cardiovascular support until such time as cardiac lesions have been excluded. 
Table 1 Definitions of septic shock

Sustained tachycardia (not necessary in the hypothermic patient), decreased peripheral pulses compared with
central pulses, delayed capillary refill (defined as $>2 \mathrm{~s})$ or flash capillary refill, altered mental status,
mottled cool extremities, or decreased urine output $(<1 \mathrm{~mL} / \mathrm{kg} / \mathrm{h})$
Hypotension $(<5$ th percentile for age) is considered confirmatory but not necessary
Despite administration of isotonic intravenous fluid bolus $\geq 40 \mathrm{~mL} / \mathrm{kg}$ in $1 \mathrm{~h}:$
- Decrease in BP (hypotension) $<5$ th percentile for age or systolic BP $<2 \mathrm{SD}$ below normal for age
Or
- Need for vasoactive drug to maintain BP in normal range (dopamine $>5 \mu \mathrm{g} / \mathrm{kg} / \mathrm{min}$ or dobutamine,
epinephrine, or norepinephrine at any dose)
Or
- Two of the following:
Unexplained metabolic acidosis: base deficit $>5.0 \mathrm{mEq} / \mathrm{L}$
Increased arterial lactate $>2$ times upper limit of normal
Oliguria: urine output $<0.5 \mathrm{~mL} / \mathrm{kg} / \mathrm{h}$
Prolonged capillary refill: $>5 \mathrm{~s}$
Core to peripheral temperature gap $>3{ }^{\circ} \mathrm{C}$

\section{Diagnostic Tests}

Once septic shock has been considered as a diagnosis, diagnostic tests should be collected as soon as possible (but without delaying the initiation of therapy). The tests required for the diagnosis of the etiology of "septic shock" differ across the world depending on the prevalent pathogens. In much of Europe and the United States of America bacterial and some viral pathogens are the most likely causes of septic shock. However in other parts of the world conditions such as malaria and dengue need to be considered and may be impossible to differentiate from bacterial sepsis clinically. One of the underlying problems with the management of severe sepsis throughout the developing world is the lack of adequate diagnostics for infectious agents. Recently, the bacterial culture rate in a large cohort of children with severe sepsis in East Africa [41] was only $12 \%$ (while $57 \%$ were positive for malaria parasites).

Culture is the usual standard for the diagnosis of severe bacterial infections. Culture unfortunately may take many hours (or days) to provide a result, and the sensitivity of blood cultures in children is limited by the small size of the blood sample that is collected [42]. However, recently multiplex PCR [43] (the LightCycler SeptiFast test) has been used for diagnosis of bloodstream infections in neonates and children. The time to result was only $6 \mathrm{~h}$, and the test may still be positive following the administration of antibiotics. This holds potential for future widespread clinical implementation, but cost is likely to be a limiting factor in many parts of the world.

The use of a wide range of markers of sepsis has been reported in the literature. It would seem that raised white cell counts are not helpful in diagnosing sepsis, while procalcitonin and $\mathrm{C}$-reactive protein may be more useful
[33]. A study in 90 children with severe sepsis or septic shock [44] showed that procalcitonin levels at both admission and $6 \mathrm{~h}$ post admission were significantly higher in septic shock patients. Similar results were shown in another study of 94 children in PICU [45]. Serum ferritin levels were associated with outcome in patients with severe sepsis or septic shock, and a ferritin level of $>500 \mathrm{ng} / \mathrm{mL}$ was associated with a $3.2(1.3-7.9)$ relative risk of death $(p=0.01)$ [46]. In many areas of the world there is limited laboratory support, and clinicians have little choice but to focus on known epidemiology and treat empirically based on most likely pathogens [47].

The presence of a raised DIC score (an 8-point score calculated from the sum of points allocated the parameters of platelet numbers, fibrinogen levels, fibrin degradation product levels and prothrombin time) was associated with increased mortality in children with sepsis and shock in a study in India [48].

\section{Management}

The themes of the currently accepted guidelines for management of pediatric septic shock are: Goal-directed, early administration of effective antibiotics; early and aggressive fluid resuscitation; rapid escalation of cardiovascular support if fluid resuscitation does not have the desired effect.

\section{Antibiotics}

Given that the negative consequences of early initiation of antibiotics are low, particularly if the antibiotics are subsequently stopped in a timely fashion (if results show that bacterial sepsis can be excluded) and given that delays in 
appropriate antibiotic administration are associated with adverse outcomes [49-52, 53••], there should be a low threshold for early administration of antibiotics. In particular the threshold for initiation of treatment for sepsis should be extremely low in children at increased risk of severe sepsis (including neonates and young infants; children with immunosuppression or malignancy or abnormalities of protective skin layers; children with traumatic injuries and burn injuries [54]; and children who have recently undergone major surgery) $[49,50]$. If infection is subsequently ruled out, then antibiotic therapy should be stopped. If a particular pathogen is identified, then antibiotic coverage can be narrowed.

There is evidence from the adult literature that delayed administration of antibiotics to patients with septic shock is associated with significant increases in mortality [52]. Likewise administration of the inappropriate antibiotic is associated with an increase in mortality [53••] while use of appropriate combination antibiotic therapy is associated with improved outcomes [51].

Centers across the world have reported that achieving early administration of antibiotics to patients with septic shock may be surprisingly difficult $[17,55 \cdot, 56,57]$ and institutions that may need to treat children with septic shock have to develop systems to ensure that broad spectrum (appropriate to the local microbiology profile) antibiotics are readily available and can be administered in appropriate pediatric dosage within a short space of time. Intravenous administration of antibiotics is the most effective way of ensuring adequate therapeutic levels.

Although there is a paucity of pediatric literature related to the pharmacodynamics and kinetics of antibiotics in severe sepsis, there is a body of evidence in the adult literature showing that antibiotic levels of drugs such as ertapenem $[58,59]$, beta-lactams and vancomycin may vary considerably in severe sepsis depending on the specific context [59-63], including albumin and creatinine levels. Drugs such as aminoglycosides may accumulate in patients with severe sepsis, but there may also be augmented excretion of antibiotics such as beta-lactams with resultant poor therapeutic levels [64]. In patients on continuous renal replacement therapy there also may be very significant differences in antibiotic levels achieved [65]. Although there is no definitive evidence that monitoring of antibiotic drug levels will improve outcomes, there is an urgent need for investigation of this particular question [66].

\section{Fluid Resuscitation}

There is strong consensus in the guidelines for the management of septic shock in children that early and aggressive fluid resuscitation is appropriate [12, 67, 68]. In addition, a number of studies have shown that where adherence with these guidelines has been achieved, there was a substantial reduction in mortality or hospital stay related to septic shock $[8,55 \cdot, 69]$.

While there is considerable debate about which fluids should be used for volume resuscitation in septic shock, there is no definitive evidence robust enough to make firm recommendations [70]. Currently fluids such as $0.9 \%$ saline and Ringer's lactate are relatively inexpensive and have not been shown to be inferior to colloids. Adult studies suggest that colloids (both albumen and starches) hold little benefit in shock [71, 72] relative to crystalloids.

Vascular access in small children, particularly those in septic shock, may be difficult, and early resort to intraosseous access may enable fluid resuscitation [73]. Once intra-osseous vascular access has been established, it is easier to provide support and appropriate analgesia to establish more secure vascular access.

Recently the FEAST study [41] provided a surprising result in demonstrating that administration of a fluid bolus (either saline or albumen) was associated with increased mortality in a group of children with a severe febrile illness in East Africa. That study was well-designed and robust, with over 3,000 patients enrolled, and intriguingly the outcome was contrary to the expectations of clinical staff involved in the study. The implications of that study remain to be elucidated. Some of the factors that may be related to the outcome in that particular group of patients include: high rates of malaria; significant anemia; lack of identification of pathogens in the majority of the patients (only $12 \%$ had positive blood cultures and there were no other tests for bacterial or viral pathogens); lack of availability of respiratory support (ventilation was not available, and in some cases access to oxygen was extremely limited). The result was particularly surprising in light of previous studies from that region demonstrating improvements in patients with severe malaria treated with fluid boluses [74, 75]. It is relevant that although early antibiotic administration, vigorous volume resuscitation, and early use of inotropic support was associated with a dramatic improvement in outcomes from severe meningococcal disease in the UK [76], early endotracheal intubation and ventilation was provided for these patients.

In the context of dengue, it has been clearly demonstrated that therapy with a limited fluid bolus $(15 \mathrm{~mL} / \mathrm{kg}$ over a $1-\mathrm{h}$ period, followed by $10 \mathrm{~mL} / \mathrm{kg}$ over the second hour) is life-saving in children with moderately severe dengue shock [77, 78]. In terms of clinical features septic shock and dengue shock clearly have some overlap although there may be some distinguishing features [79].

In countries where respiratory support is not always available, a more conservative approach to fluid administration may well be justified in septic shock [80]. This may be even more relevant in children with significant 
malnutrition, although the evidence base for this is extremely limited [81, 82].

Once patients have been resuscitated, a conservative approach to fluid therapy should be employed (particularly in patients with renal dysfunction) as fluid overload has been clearly associated with increased mortality (see below).

\section{Cardiovascular Support}

Guidelines [12, 83] recommend the use of dopamine in patients with septic shock who have failed to respond adequately to $60 \mathrm{~mL} / \mathrm{kg}$ or more of fluid resuscitation. Importantly, initiation of this support should not wait until central venous access has been established (although it is safer to administer vasoactive drugs through central venous access together with very close hemodynamic monitoring). At a later stage in the resuscitation process, there are recommendations for different combinations of cardiovascular drugs, depending on the particular hemodynamic profile of the patient. It is important to note that clinical profiles may change over time in individual patients, and therapy must be monitored (this may include invasive measurements ranging from arterial and central lines to pulmonary artery catheters; mixed or superior vena cava venous saturation; or noninvasive Doppler studies) if not continuously, at least very frequently. In the setting of fluid and inotropic refractory shock it is suggested that epinephrine could be used instead of dopamine for the patient with "cold shock", while norepinephrine could be added for the patients with "warm shock". Arginine vasopressin or analogues such as terlipressin have also been used in small numbers of patients with catecholamine-refractory vasodilatory shock [84-86].

\section{Respiratory Support}

Early initiation of respiratory support is highlighted in all the guidelines. Certainly, oxygen therapy should be initiated early in shocked children, although there are concerns about the impact of hyperoxia on tissue damage, particularly in patients with limited anti-oxidant capacity [87]. Once initial resuscitation has been achieved, oxygen therapy should be titrated to avoid hyperoxia. There is no evidence that hypocarbia during ventilation for sepsis is beneficial (and real evidence that over-ventilation may reduce preload to the right heart with subsequent decrease in cardiac output and can also lead to cerebral vasoconstriction and secondary ischemic brain injury), and some evidence that hypercarbia is not harmful and may well be beneficial [88]. In all cases ventilation should be provided using lung-protective strategies incorporating a tidal volume of approximately $6 \mathrm{~mL} / \mathrm{kg}$ and a peak pressure of $<30 \mathrm{~cm} \mathrm{H}_{2} \mathrm{O}$ [89]. Strategies such as high-frequency oscillatory ventilation and prone ventilation may be useful adjuncts in patients with acute respiratory distress syndrome.

While early initiation of ventilator support has been recommended, the endotracheal intubation of patients in septic shock may be a high-risk procedure with morbidity related to the agents used for anesthesia [90]. Etomidate is not recommended because of its effects on the adrenocorticoid axis [91, 92]; ketamine has been recommended as a useful agent as it tends to cause less hypotension (although patients with depleted catecholamine stores may be at risk for hypotension), while propofol is not recommended because of the potentiation of its effects encountered during shock [93]. Initiation of positive-pressure ventilation may cause a drop in cardiac output in patients who are relatively hypovolemic (although positive-pressure ventilation may also improve cardiac output in the setting of left ventricular dysfunction). Thus, ideally, patients should be adequately volume resuscitated and started on inotropic infusions (by peripheral vein if necessary) prior to intubation.

The use of high-flow humidified nasal oxygen therapy may be a useful adjunct to respiratory support in pediatric septic shock over a range of age-groups, as it has shown benefits in respiratory support in a variety of contexts [94-96].

In general, the guidelines have focused on clinically apparent hemodynamic goals of treatment, such as return of normal blood pressure, heart rate and capillary refill. Some studies have added other goals, such as superior vena cava saturations [8]. In that study there was a substantial improvement in mortality in the group where superior vena caval saturations were targeted, but the actual difference in therapy was that these patients received more fluid in the first hour of resuscitation. The microcirculation in pediatric shock has recently been reviewed by Top et al. [97], showing that failure of return to normal of the micro-circulation is related to poor outcomes from septic shock, and suggesting that there may be a clinical role in the future for techniques that assess the micro-circulation in children with septic shock. Currently assessment of the micro-circulation is difficult in the clinical context.

\section{Renal Support Therapy}

Mortality in children with septic shock who require renal replacement therapy may be very high [98], particularly in younger children who require significant inotropic support. Several studies of the need for renal support therapy in septic shock have highlighted the fact that significant fluid overload in patients prior to the onset of dialysis is associated with higher mortality $[99,100]$. There is no evidence suggesting that particular forms of renal support therapy (e.g., peritoneal dialysis, hemodialysis or continuous hemofiltration) are of particular benefit in septic shock, although technical considerations may give rise to 
preferences for the mode of support used. There is some limited evidence that plasmapheresis may improve outcomes from severe sepsis [101], while a recent study reported that in a group of 12 previously well patients with multi-system organ failure related to septic shock ( 8 with meningococcemia), early initiation of therapeutic plasma exchange was associated with good quality survival in 11 [101].

\section{Pyrexia and Management}

Treatment of pyrexia has recently been reviewed by Launey et al. [102]. Pyrexia is closely associated with infection, and studies on the adverse effects of hyperpyrexia on neurological injury have driven intensivists towards an aggressive approach to reduce fever in ICU patients. There is considerable experimental evidence that pyrexia may be beneficial in terms of clearing infection and surviving sepsis. Thus there is little indication for aggressive attempts to reduce pyrexia in patients with severe sepsis, unless complications of hyperpyrexia are possible.

\section{Tight Glucose Control}

Hyperglycemia has been related to adverse outcomes in critically ill children in a variety of situations for some years [103]. Recently, the literature on adults has focused on "tight glucose control" as an essential component of therapy for severe sepsis, although this has been controversial. Despite earlier positive studies, there are some recent studies that suggest that the adverse consequences of tight glucose control may outweigh the benefits [104]. Children may have a different physiological basis for hyperglycemia in severe illness relative to adults, and there is very limited data to support this approach in children with septic shock. However, persistent hyperglycemia may be a marker of inadequate resuscitation (or ongoing stress). Severe hyperglycemia should probably be treated with insulin infusions (cautiously).

\section{Steroids}

The guidelines for management of septic shock recommend the administration of hydrocortisone to children with catecholamine-resistant septic shock when they are at risk of adrenal insufficiency. In the largest study of children with severe sepsis to date, the use of steroids was not associated with any significant improvement in outcome [105].

A retrospective study of children with systemic inflammatory response syndrome and fluid refractory shock who had received low-dose hydrocortisone and fludrocortisone supplementation showed no difference in duration of vasopressor support, but the septic shock group who had received fludrocortisone and hydrocortisone received a shorter duration of support with norepinephrine [106].

\section{Adherence to Bundles}

Since the publication of the Surviving Sepsis Guidelines and the updated guidelines [12, 13], a number of studies have shown that adherence to guidelines has been associated with improved patient outcomes [55•, 69]. However, several studies have shown that implementation of guidelines may not be straightforward, even in settings which are relatively well resourced [55•, 107].

Paul et al. [55•] demonstrated that although they had poor adherence to guidelines, adherence was associated with significantly shorter hospital stay. Recently Larsen et al. [17] implemented a protocol for the recognition and management of septic shock in their emergency department. Over a 5-year period, they identified 297 children who met septic shock criteria. Implementation of the guideline was associated with a decrease in duration of hospital stay, but no change in mortality. However, this was in the context of a mortality of $6.3 \%$. Han et al. [69] showed a substantially lower mortality in children presenting to a community hospital with septic shock where providers followed guidelines for early reversal of shock.

The development of a particular septic shock team has been shown to significantly improve the outcomes in adults with septic shock [108].

As part of developing systems and structures for management of children in septic shock, it is important to review and consider the need for stabilization and transport of children with septic shock [109]. It is also important to focus on meeting the particular needs of children who are poor; at particular risk for septic shock; or both [110].

\section{Nosocomial Infection}

Children with septic shock may have immunoparalysis [111], and particular attention must be paid to ensuring that risks of nosocomial infection are decreased as far as possible [111]. It is particularly important in environments where many children have infections, and the number of available staff is limited to focus on the needs for reduction of patient-to-patient transmission of infection.

\section{Conclusions}

Septic shock remains a significant cause of pediatric mortality and morbidity across the world, despite advances in both public health and critical care. Implementation of guidelines has been associated with improvements in outcomes, although compliance rates remain surprisingly low. Importantly, the major components of the therapy-such as early antibiotic administration, fluid resuscitation and ongoing interventions such as inotropic support-are not 
Table 2 Do's and Don'ts in the recognition and management of septic shock in children: some key points

Do's

Support programs focused on reducing the risks of severe sepsis, particularly in children who are at high risk from infection

Think of sepsis as a cause of shock

Treat early with antibiotics appropriate to likely pathogens

Consider the full range of pathogens that are possible in the context in which the patient is found

Where possible use diagnostic tests that will provide timely and accurate answers

Resuscitate vigorously (bearing in mind the context and the availability of support such as mechanical ventilation)

Set appropriate goals for resuscitation, bearing in mind that the micro-circulation may be critically important

Provide early renal replacement therapy, particularly in patients who have evidence of fluid overload (you need to monitor intake and output carefully with this in mind)

Use bundles and focus on quality control programs to improve the outcomes of severe sepsis in children

Beware of possible immunoparalysis, high risks of nosocomial infection in these patients and consider addressing any deficiencies in control of nosocomial infection in your environment.

Don'ts

Don't wait for hypotension before initiating therapy for septic shock (i.e. don't use definitions that have been developed with research projects in mind, rather use clinical definitions that have been developed on a pragmatic basis)

Don't delay initiation of therapy while diagnostic tests are carried out (this is an additional reason as to why molecular diagnostic techniques may be so useful in the future)

Don't give excessive fluid after initial resuscitation

Don't focus on numbers without considering important endpoints (tissue perfusion etc.)

particularly expensive and can be provided to many children (even in resource-limited settings). Unfortunately, management of septic shock may be more complex in resource-limited settings for a variety of reasons, including the range of pathogens, underlying factors such as chronic disease and malnutrition, and limited access to respiratory support. Particular do's and don'ts in the recognition and management of septic shock have been summarized in Table 2.

While optimization of therapy for severe sepsis in resource-limited environments must become a central focus for future research, there is a need for greater understanding of how effective and timely therapy can be made available to children in all settings. There is a hope that with early and effective systems to prevent severe sepsis where possible but also to treat severe sepsis appropriately substantial reductions in pediatric mortality and morbidity across the world can be achieved.
Conflict of interest No potential conflicts of interest relevant to this article were reported.

\section{References}

Papers of particular interest, published recently, have been highlighted as:

- Of importance;

•- Of major importance

1. Segal S, Pollard AJ. Vaccines against bacterial meningitis. $\mathrm{Br}$ Med Bull. 2004;72:65-81.

2. Agrawal S, Nadel S. Acute bacterial meningitis in infants and children: epidemiology and management. Paediatr Drugs. 2011;13(6):385-400.

3. The State of the World's Children 2011. New York: United Nations Children's Fund (UNICEF); 2011.

4. Bahl R, Martines J, Ali N, Bhan MK, Carlo W, Chan KY, Darmstadt GL, Hamer DH, Lawn JE, McMillan DD, et al. Research priorities to reduce global mortality from newborn infections by 2015. Pediatr Infect Dis J. 2009;28(1 Suppl):S43-8.

5. Mangia CM, Kissoon N, Branchini OA, Andrade MC, Kopelman BI, Carcillo J: Bacterial sepsis in Brazilian children: a trend analysis from 1992 to 2006. PLoS One. 2011;6(6):e14817. An interesting paper from Latin America, showing that while overall mortality from pediatric sepsis has declined, there has been little change in the in hospital mortality from patients presenting with sepsis.

6. DuPont HL, Spink WW. Infections due to gram-negative organisms: an analysis of 860 patients with bacteremia at the University of Minnesota Medical Center, 1958-1966. Medicine. 1969;48(4):307-32.

7. Angus DC, Linde-Zwirble WT, Lidicker J, Clermont G, Carcillo J, Pinsky MR. Epidemiology of severe sepsis in the United States: analysis of incidence, outcome, and associated costs of care. Crit Care Med. 2001;29(7):1303-10.

8. de Oliveira CF, de Oliveira DS, Gottschald AF, Moura JD, Costa GA, Ventura AC, Fernandes JC, Vaz FA, Carcillo JA, Rivers EP, et al. ACCM/PALS haemodynamic support guidelines for paediatric septic shock: an outcomes comparison with and without monitoring central venous oxygen saturation. Intensive Care Med. 2008;34(6):1065-75.

9. Carcillo JA, Kuch BA, Han YY, Day S, Greenwald BM, McCloskey KA, Pearson-Shaver AL, Orr RA. Mortality and functional morbidity after use of PALS/APLS by community physicians. Pediatrics. 2009;124(2):500-8.

10. Buysse CM, Raat H, Hazelzet JA, Hop WC, Maliepaard M, Joosten KF. Surviving meningococcal septic shock: health consequences and quality of life in children and their parents up to 2 years after pediatric intensive care unit discharge. Crit Care Med. 2008;36(2):596-602.

11. Buysse CM, Raat H, Hazelzet JA, Hulst JM, Cransberg K, Hop WC, Vermunt LC, Utens EM, Maliepaard M, Joosten KF. Longterm health status in childhood survivors of meningococcal septic shock. Arch Pediatr Adolesc Med. 2008;162(11):1036-41.

12. Brierley J, Carcillo JA, Choong K, Cornell T, Decaen A, Deymann A, Doctor A, Davis A, Duff J, Dugas MA, et al. Clinical practice parameters for hemodynamic support of pediatric and neonatal septic shock: 2007 update from the American College of Critical Care Medicine. Crit Care Med. 2009;37(2):666-88.

13. Dellinger RP, Levy MM, Carlet JM, Bion J, Parker MM, Jaeschke R, Reinhart K, Angus DC, Brun-Buisson C, Beale R, 
et al. Surviving Sepsis Campaign: international guidelines for management of severe sepsis and septic shock: 2008. Crit Care Med. 2008;36(1):296-327.

14. Levy MM, Dellinger RP, Townsend SR, Linde-Zwirble WT, Marshall JC, Bion J, Schorr C, Artigas A, Ramsay G, Beale R, et al. The Surviving Sepsis Campaign: results of an international guideline-based performance improvement program targeting severe sepsis. Crit Care Med. 2010;38(2):367-74.

15. Peters MJ, Brierley J. Back to basics in septic shock. Intensive Care Med. 2008;34(6):991-3.

16. Carcillo JA. Reducing the global burden of sepsis in infants and children: a clinical practice research agenda. Pediatr Crit Care Med. 2005;6(3 Suppl):S157-64.

17. Larsen GY, Mecham N, Greenberg R. An emergency department septic shock protocol and care guideline for children initiated at triage. Pediatrics. 2011;127(6):e1585-92.

18. Carcillo JA, Davis AL, Zaritsky A. Role of early fluid resuscitation in pediatric septic shock. JAMA. 1991;266(9):1242-5.

19. Aneja R, Carcillo J. Differences between adult and pediatric septic shock. Minerva Anestesiol. 2011;77(10):986-92.

20. Wynn JL, Cvijanovich NZ, Allen GL, Thomas NJ, Freishtat RJ, Anas N, Meyer K, Checchia PA, Lin R, Shanley TP, et al.: The influence of developmental age on the early transcriptomic response of children with septic shock. Mol Med. 2011;17(11-12): 1146-1156.

21. Thompson M, Mayon-White R, Harnden A, Perera R, McLeod $\mathrm{D}$, Mant D. Using vital signs to assess children with acute infections: a survey of current practice. Br J Gen Pract. 2008; 58(549):236-41.

22. Thompson M, Van den Bruel A, Verbakel J, Lakhanpaul M, Haj-Hassan T, Stevens R, Moll H, Buntinx F, Berger M, Aertgeerts $\mathrm{B}$, et al. Systematic review and validation of prediction rules for identifying children with serious infections in emergency departments and urgent-access primary care. Health Technol Assess. 2012;16(15):1-100.

23. Thompson MJ, Ninis N, Perera R, Mayon-White R, Phillips C, Bailey L, Harnden A, Mant D, Levin M. Clinical recognition of meningococcal disease in children and adolescents. Lancet. 2006;367(9508):397-403.

24. Opal SM. Concept of PIRO as a new conceptual framework to understand sepsis. Pediatr Crit Care Med. 2005;6(3 Suppl): S55-60.

25. Ceneviva G, Paschall JA, Maffei F, Carcillo JA. Hemodynamic support in fluid-refractory pediatric septic shock. Pediatrics. 1998

102(2):e19.

26. Mercier JC, Beaufils F, Hartmann JF, Azema D. Hemodynamic patterns of meningococcal shock in children. Crit Care Med. 1988;16(1):27-33.

27. Brierley J, Peters MJ. Distinct hemodynamic patterns of septic shock at presentation to pediatric intensive care. Pediatrics. 2008;122(4):752-9.

28. Lister P, Reynolds F, Parslow R, Chan A, Cooper M, Plunkett A, Riphagen S, Peters M. Swine-origin influenza virus H1N1, seasonal influenza virus, and critical illness in children. Lancet. 2009;374(9690):605-7.

29. Vanagt WY, Lutgens SP, van Loo IH, Wolffs PF, van Well GT. Paediatric sepsis-like illness and human parechovirus. Arch Dis Child. 2012;97(5):482-3.

30. Rekhtman D, Wolf DG, Levy-Khademi F, Averbuch D, Kerem E, Wexler ID. Influenza A infection in young infants. Arch Dis Child. 2011;96(11):1085-7.

31. Maitland K, Pamba A, Newton CR, Levin M. Response to volume resuscitation in children with severe malaria. Pediatr Crit Care Med. 2003;4(4):426-31.
32. - Van den Bruel A, Haj-Hassan T, Thompson M, Buntinx F, Mant D, European Research Network on Recognising Serious Infection i: Diagnostic value of clinical features at presentation to identify serious infection in children in developed countries: a systematic review. Lancet. 2010;375(9717):834-45. Paper highlighting the difficult $y$ of recognising serious infection in young children, even in developed countries.

33. Van den Bruel A, Thompson MJ, Haj-Hassan T, Stevens R, Moll H, Lakhanpaul M, Mant D. Diagnostic value of laboratory tests in identifying serious infections in febrile children: systematic review. BMJ. 2011;342:d3082.

34. Van den Bruel A, Thompson M, Buntinx F, Mant D. Clinicians' gut feeling about serious infections in children: observational study. BMJ. 2012;345:e6144.

35. Carcillo JA, Fields AI, American College of Critical Care Medicine Task Force Committee M: Clinical practice parameters for hemodynamic support of pediatric and neonatal patients in septic shock. Crit Care Med. 2002;30(6):1365-78.

36. Goldstein B, Giroir B, Randolph A, International Consensus Conference on Pediatric S: International pediatric sepsis consensus conference: definitions for sepsis and organ dysfunction in pediatrics. Pediatr Crit Care Med. 2005;6(1):2-8.

37. Weiss SL, Parker B, Bullock ME, Swartz S, Price C, Wainwright MS, Goodman DM: Defining pediatric sepsis by different criteria: discrepancies in populations and implications for clinical practice. Pediatr Crit Care Med. 2012;13(4):e219-26.

38. Otieno H, Were E, Ahmed I, Charo E, Brent A, Maitland K. Are bedside features of shock reproducible between different observers? Arch Dis Child. 2004;89(10):977-9.

39. Pamba A, Maitland K. Capillary refill: prognostic value in Kenyan children. Arch Dis Child. 2004;89(10):950-5.

40. Rady MY, Nightingale P, Little RA, Edwards JD. Shock index: a re-evaluation in acute circulatory failure. Resuscitation. 1992;23(3):227-34.

41. Maitland K, Kiguli S, Opoka RO, Engoru C, Olupot-Olupot P, Akech SO, Nyeko R, Mtove G, Reyburn H, Lang T, Brent B, Evans JA, Tibenderana JK, Crawley J, Russell EC, Levin M, Babiker AG, Gibb DM. Feast trial group. Mortality after fluid bolus in African children with severe infection. N Engl J Med. 2011;364(26):2483-95.

42. Connell TG, Rele M, Cowley D, Buttery JP, Curtis N. How reliable is a negative blood culture result? Volume of blood submitted for culture in routine practice in a children's hospital. Pediatrics. 2007;119(5):891-6.

43. Lucignano B, Ranno S, Liesenfeld O, Pizzorno B, Putignani L, Bernaschi P, Menichella D. Multiplex PCR allows rapid and accurate diagnosis of bloodstream infections in newborns and children with suspected sepsis. J Clin Microbiol. 2011;49(6): 2252-8.

44. Fioretto JR, Borin FC, Bonatto RC, Ricchetti SM, Kurokawa CS, de Moraes M, Carpi MF, Padovani CR, Martin JG. Procalcitonin in children with sepsis and septic shock. J Pediatr (Rio J). 2007;83(4):323-8.

45. Rey C, Los Arcos M, Concha A, Medina A, Prieto S, Martinez $\mathrm{P}$, Prieto B. Procalcitonin and C-reactive protein as markers of systemic inflammatory response syndrome severity in critically ill children. Intensive Care Med. 2007;33(3):477-84.

46. Garcia PC, Longhi F, Branco RG, Piva JP, Lacks D, Tasker RC. Ferritin levels in children with severe sepsis and septic shock. Acta Paediatr. 2007;96(12):1829-31.

47. Berkley JA, Maitland K, Mwangi I, Ngetsa C, Mwarumba S, Lowe BS, Newton CR, Marsh K, Scott JA, English M. Use of clinical syndromes to target antibiotic prescribing in seriously ill children in malaria endemic area: observational study. BMJ. 2005;330(7498):995. 
48. Khemani RG, Bart RD, Alonzo TA, Hatzakis G, Hallam D, Newth CJ. Disseminated intravascular coagulation score is associated with mortality for children with shock. Intensive Care Med. 2009;35(2):327-33.

49. Zubert S, Funk DJ, Kumar A. Antibiotics in sepsis and septic shock: like everything else in life, timing is everything. Crit Care Med. 2010;38(4):1211-2.

50. Sharma S, Kumar A: Antimicrobial management of sepsis and septic shock. Clin Chest Med. 2008;29(4):677-87, ix.

51. Kumar A, Zarychanski R, Light B, Parrillo J, Maki D, Simon D, Laporta D, Lapinsky S, Ellis P, Mirzanejad Y, et al. Early combination antibiotic therapy yields improved survival compared with monotherapy in septic shock: a propensity-matched analysis. Crit Care Med. 2010;38(9):1773-85.

52. Kumar A, Roberts D, Wood KE, Light B, Parrillo JE, Sharma S, Suppes R, Feinstein D, Zanotti S, Taiberg L, et al. Duration of hypotension before initiation of effective antimicrobial therapy is the critical determinant of survival in human septic shock. Crit Care Med. 2006;34(6):1589-96.

53. • Kumar A, Ellis P, Arabi Y, Roberts D, Light B, Parrillo JE, Dodek P, Wood G, Kumar A, Simon D, et al.: Initiation of inappropriate antimicrobial therapy results in a fivefold reduction of survival in human septic shock. Chest. 2009;136(5):1237-48. Important paper showing the impact of inappropriate antibiotic therapy on the survival of patients with septic shock.

54. Young AE, Thornton KL: Toxic shock syndrome in burns: diagnosis and management. Arch Dis Child Educ Pract Ed. 2007;92(4):ep97-100.

55. • Paul R, Neuman MI, Monuteaux MC, Melendez E: Adherence to PALS Sepsis guidelines and hospital length of stay. Pediatrics. 2012;130(2):e273-80. Recent study demonstrating how infrequently they were able to adhere to the sepsis guidelines, but how adherence substantially reduced length of hospital stay.

56. Jones AE, Shapiro NI, Roshon M: Implementing early goaldirected therapy in the emergency setting: the challenges and experiences of translating research innovations into clinical reality in academic and community settings. Acad Emerg Med. 2007;14(11):1072-8.

57. Cruz AT, Perry AM, Williams EA, Graf JM, Wuestner ER, Patel B. Implementation of goal-directed therapy for children with suspected sepsis in the emergency department. Pediatrics. 2011;127(3):e758-66.

58. Bassetti M, Righi E, Fasce R, Molinari MP, Rosso R, Di Biagio A, Mussap M, Pallavicini FB, Viscoli C. Efficacy of ertapenem in the treatment of early ventilator-associated pneumonia caused by extended-spectrum beta-lactamase-producing organisms in an intensive care unit. J Antimicrob Chemother. 2007;60(2):433-5.

59. Ulldemolins M, Roberts JA, Rello J, Paterson DL, Lipman J. The effects of hypoalbuminaemia on optimizing antibacterial dosing in critically ill patients. Clin Pharmacokinet. 2011;50(2): 99-110.

60. Roberts JA, Taccone FS, Udy AA, Vincent JL, Jacobs F, Lipman J. Vancomycin dosing in critically ill patients: robust methods for improved continuous-infusion regimens. Antimicrob Agents Chemother. 2011;55(6):2704-9.

61. Sinnollareddy MG, Roberts MS, Lipman J, Roberts JA. Betalactam pharmacokinetics and pharmacodynamics in critically ill patients and strategies for dose optimization: a structured review. Clin Exp Pharmacol Physiol. 2012;39(6):489-96.

62. Ulldemolins M, Roberts JA, Lipman J, Rello J. Antibiotic dosing in multiple organ dysfunction syndrome. Chest. 2011;139(5):1210-20.

63. Ulldemolins M, Roberts JA, Wallis SC, Rello J, Lipman J. Flucloxacillin dosing in critically ill patients with hypoalbuminaemia: special emphasis on unbound pharmacokinetics. J Antimicrob Chemother. 2010;65(8):1771-8.
64. Udy AA, Putt MT, Boots RJ, Lipman J. ARC-augmented renal clearance. Curr Pharm Biotechnol. 2011;12(12):2020-9.

65. Roberts DM, Roberts JA, Roberts MS, Liu X, Nair P, Cole L, Lipman J, Bellomo R, Investigators RRTS: Variability of antibiotic concentrations in critically ill patients receiving continuous renal replacement therapy: a multicentre pharmacokinetic study. Crit Care Med. 2012;40(5):1523-28.

66. Sime FB, Roberts MS, Peake SL, Lipman J, Roberts JA. Does beta-lactam pharmacokinetic variability in critically ill patients justify therapeutic drug monitoring? a systematic review. Ann Intensive Care. 2012;2(1):35.

67. Dellinger RP, Levy MM, Carlet JM, Bion J, Parker MM, Jaeschke R, Reinhart K, Angus DC, Brun-Buisson C, Beale R, et al. Surviving Sepsis Campaign: international guidelines for management of severe sepsis and septic shock: 2008. Intensive Care Med. 2008;34(1):17-60.

68. Carcillo JA. Pediatric septic shock and multiple organ failure. Crit Care Clin. 2003;19(3):413-40. viii.

69. Han YY, Carcillo JA, Dragotta MA, Bills DM, Watson RS, Westerman ME, Orr RA. Early reversal of pediatric-neonatal septic shock by community physicians is associated with improved outcome. Pediatrics. 2003;112(4):793-9.

70. Akech S, Ledermann H, Maitland K. Choice of fluids for resuscitation in children with severe infection and shock: systematic review. BMJ. 2010;341:c4416.

71. Gattas DJ, Dan A, Myburgh J, Billot L, Lo S, Finfer S, Committee CM. Fluid resuscitation with $6 \%$ hydroxyethyl starch (130/0.4) in acutely ill patients: an updated systematic review and meta-analysis. Anesth Analg. 2012;114(1):159-69.

72. Finfer S, Liu B, Taylor C, Bellomo R, Billot L, Cook D, Du B, McArthur C, Myburgh J, Investigators ST. Resuscitation fluid use in critically ill adults: an international cross-sectional study in 391 intensive care units. Crit Care. 2010;14(5):R185.

73. Voigt J, Waltzman M, Lottenberg L. Intraosseous vascular access for in-hospital emergency use: a systematic clinical review of the literature and analysis. Pediatr Emerg Care. 2012; 28(2):185-99.

74. Pamba A, Maitland K. Fluid management of severe falciparum malaria in African children. Trop Doct. 2004;34(2):67-70.

75. Akech S, Gwer S, Idro R, Fegan G, Eziefula AC, Newton CR, Levin M, Maitland K. Volume expansion with albumin compared to gelofusine in children with severe malaria: results of a controlled trial. PLoS Clin Trials. 2006;1(5):e21.

76. Booy R, Habibi P, Nadel S, de Munter C, Britto J, Morrison A, Levin M, Meningococcal Research G. Reduction in case fatality rate from meningococcal disease associated with improved healthcare delivery. Arch Dis Child. 2001;85(5):386-90.

77. Wills BA, Nguyen MD, Ha TL, Dong TH, Tran TN, Le TT, Tran VD, Nguyen TH, Nguyen VC, Stepniewska K, et al. Comparison of three fluid solutions for resuscitation in dengue shock syndrome. N Engl J Med. 2005;353(9):877-89.

78. Ranjit S, Kissoon N, Jayakumar I. Aggressive management of dengue shock syndrome may decrease mortality rate: a suggested protocol. Pediatr Crit Care Med. 2005;6(4):412-9.

79. Ranjit S, Kissoon N, Gandhi D, Dayal A, Rajeshwari N, Kamath SR. Early differentiation between dengue and septic shock by comparison of admission hemodynamic, clinical, and laboratory variables: a pilot study. Pediatr Emerg Care. 2007;23(6):368-75.

80. Santhanam I, Sangareddi S, Venkataraman S, Kissoon N, Thiruvengadamudayan V, Kasthuri RK. A prospective randomized controlled study of two fluid regimens in the initial management of septic shock in the emergency department. Pediatr Emerg Care. 2008;24(10):647-55.

81. Akech SO, Karisa J, Nakamya P, Boga M, Maitland K. Phase II trial of isotonic fluid resuscitation in Kenyan children with 
severe malnutrition and hypovolaemia. BMC Pediatr. 2010; 10:71.

82. Maitland K, Newton C, English M. Intravenous fluids for seriously ill children. Lancet. 2004;363(9404):242-3.

83. Brierley J, Choong K, Cornell T, Decaen A, Deymann A, Doctor A, Davis A, Duff J, Dugas MA, Duncan A, et al.: 2007 American College of Critical Care Medicine clinical practice parameters for hemodynamic support of pediatric and neonatal septic shock. Crit Care Med. 2009;37(2):666-88.

84. Efrati O, Modan-Moses D, Vardi A, Matok I, Bazilay Z, Paret G. Intravenous arginine vasopressin in critically ill children: is it beneficial? Shock. 2004;22(3):213-7.

85. Agrawal A, Singh VK, Varma A, Sharma R. Therapeutic applications of vasopressin in pediatric patients. Indian Pediatr. 2012;49(4):297-309.

86. Biban P, Gaffuri M. Vasopressin and terlipressin in neonates and children with refractory septic shock. Curr Drug Metabol. 2012 [Epub ahead of print].

87. Motoyama T, Okamoto K, Kukita I, Hamaguchi M, Kinoshita $\mathrm{Y}$, Ogawa H. Possible role of increased oxidant stress in multiple organ failure after systemic inflammatory response syndrome. Crit Care Med. 2003;31(4):1048-52.

88. Laffey JG, O'Croinin D, McLoughlin P, Kavanagh BP. Permissive hypercapnia-role in protective lung ventilatory strategies. Intensive Care Med. 2004;30(3):347-56.

89. Prodhan P, Noviski N. Pediatric acute hypoxemic respiratory failure: management of oxygenation. J Intensive Care Med. 2004;19(3):140-53.

90. Zelicof-Paul A, Smith-Lockridge A, Schnadower D, Tyler S, Levin S, Roskind C, Dayan P. Controversies in rapid sequence intubation in children. Curr Opin Pediatr. 2005;17(3):355-62.

91. Zuckerbraun NS, Pitetti RD, Herr SM, Roth KR, Gaines BA, King C. Use of etomidate as an induction agent for rapid sequence intubation in a pediatric emergency department. Acad Emerg Med. 2006;13(6):602-9.

92. den Brinker M, Hokken-Koelega AC, Hazelzet JA, de Jong FH, Hop WC, Joosten KF. One single dose of etomidate negatively influences adrenocortical performance for at least $24 \mathrm{~h}$ in children with meningococcal sepsis. Intensive Care Med. 2008;34(1): 163-8.

93. Johnson KB, Egan TD, Kern SE, White JL, McJames SW, Syroid $\mathrm{N}$, Whiddon $\mathrm{D}$, Church $\mathrm{T}$. The influence of hemorrhagic shock on propofol: a pharmacokinetic and pharmacodynamic analysis. Anesthesiology. 2003;99(2):409-20.

94. Lenglet H, Sztrymf B, Leroy C, Brun P, Dreyfuss D, Ricard JD. Humidified high flow nasal oxygen during respiratory failure in the emergency department: feasibility and efficacy. Respir Care. 2012;57(11):1873-8.

95. Sztrymf B, Messika J, Bertrand F, Hurel D, Leon R, Dreyfuss D, Ricard JD. Beneficial effects of humidified high flow nasal oxygen in critical care patients: a prospective pilot study. Intensive Care Med. 2011;37(11):1780-6.

96. Wilkinson D, Andersen C, O'Donnell CP, De Paoli AG: High flow nasal cannula for respiratory support in preterm infants. Cochrane Database Syst Rev. 2011;11(5):CD006405.
97. Top AP, Tasker RC, Ince C. The microcirculation of the critically ill pediatric patient. Crit Care. 2011;15(2):213.

98. Santiago MJ, Lopez-Herce J, Urbano J, Solana MJ, del Castillo J, Ballestero Y, Botran M, Bellon JM. Clinical course and mortality risk factors in critically ill children requiring continuous renal replacement therapy. Intensive Care Med. 2010;36(5):843-9.

99. Hayes LW, Oster RA, Tofil NM, Tolwani AJ. Outcomes of critically ill children requiring continuous renal replacement therapy. J Crit Care. 2009;24(3):394-400.

100. Brophy PD. Renal supportive therapy for pediatric acute kidney injury in the setting of multiorgan dysfunction syndrome/sepsis. Semin Nephrol. 2008;28(5):457-69.

101. Qu L, Kiss JE, Dargo G, Carcillo JA. Outcomes of previously healthy pediatric patients with fulminant sepsis-induced multisystem organ failure receiving therapeutic plasma exchange. J Clin Apheresis. 2011;26(4):208-13.

102. Launey Y, Nesseler N, Malledant Y, Seguin P. Clinical review: fever in septic ICU patients-friend or foe? Crit Care. 2011; 15(3):222.

103. Preissig CM, Rigby MR. Pediatric critical illness hyperglycemia: risk factors associated with development and severity of hyperglycemia in critically ill children. J Pediatr. 2009;155(5):734-9.

104. Flower O, Finfer S. Glucose control in critically ill patients. Intern Med J. 2012;42(1):4-6.

105. Zimmerman JJ, Williams MD. Adjunctive corticosteroid therapy in pediatric severe sepsis: observations from the RESOLVE study. Pediatr Crit Care Med. 2011;12(1):2-8.

106. Hebbar KB, Stockwell JA, Fortenberry JD. Clinical effects of adding fludrocortisone to a hydrocortisone-based shock protocol in hypotensive critically ill children. Intensive Care Med. 2011;37(3):518-24.

107. Inwald DP, Tasker RC, Peters MJ, Nadel S, Paediatric Intensive Care Society Study G: Emergency management of children with severe sepsis in the United Kingdom: the results of the Paediatric Intensive Care Society sepsis audit. Arch Dis Child. 2009; 94(5):348-53.

108. Schramm GE, Kashyap R, Mullon JJ, Gajic O, Afessa B. Septic shock: a multidisciplinary response team and weekly feedback to clinicians improve the process of care and mortality. Crit Care Med. 2011;39(2):252-8.

109. Lampariello S, Clement M, Aralihond AP, Lutman D, Montgomery MA, Petros AJ, Ramnarayan P. Stabilisation of critically ill children at the district general hospital prior to intensive care retrieval: a snapshot of current practice. Arch Dis Child. 2010;95(9):681-5.

110. Gavidia R, Fuentes SL, Vasquez R, Bonilla M, Ethier MC, Diorio C, Caniza M, Howard SC, Sung L: Low socioeconomic status is associated with prolonged times to assessment and treatment, sepsis and infectious death in pediatric Fever in el salvador. PloS One. 2012;7(8):e43639.

111. Hall MW, Knatz NL, Vetterly C, Tomarello S, Wewers MD, Volk HD, Carcillo JA. Immunoparalysis and nosocomial infection in children with multiple organ dysfunction syndrome. Intensive Care Med. 2011;37(3):525-32. 